\title{
Research Efficiency Assessment of Colombian Public Universities 2003-2012: Data Envelopment Analysis
}

\section{Evaluación de la Eficiencia Investigativa de las Universidades Públicas Colombianas 2003-2012 Utilizando el Análisis Envolvente de Datos}

\author{
DOI: http://dx.doi.org/10.17981/ingecuc.11.2.2015.10
}

Review Article - Reception Date: September 6, 2014 - Acceptance Date: July 31, 2015

Gabriel Yáñez Canal

Doctor in Sciences-Specialist in Educational Mathematics, Universidad Industrial de Santander. Bucaramanga (Colombia). gyanez@uis.edu.co

\section{Ana Patricia García Amado}

BS in Mathematics, Universidad Industrial de Santander. Bucaramanga (Colombia). anna.garciamado@gmail.com

Manuela González Hurtado

BS in Mathematics, Universidad Industrial de Santander. Bucaramanga (Colombia). manuelavatar@gmail.com

To reference paper:

G. Yáñez Canal, A. P. García Amado and M. González Hurtado., "Research Efficiency Assessment of Colombian Public Universities 2003-2012: Data Envelopment Analysis," INGE CUC, vol. 11, no. 2, pp. 97-108, 2015. DOI: http://dx.doi. org/10.17981/ingecuc.11.2.2015.10

\begin{abstract}
In 2003, the process of public universities evaluation began. For this purpose, a set of performance indicators constructed by the Public University System (SUE by its acronym in Spanish) in alliance with the Ministry of National Education (MEN) was used. In an effort to know about the research efficiency level that public universities had in the period 2003-2012, an analysis of the results of these indicators was executed using Data Envelopment Analysis. In particular, the productoriented CCR model was applied. Although many universities have experienced a sustained development in some of the indicators analyzed and show high relative levels of efficiency, the results show that, as a whole, the Public University System has still much to improve regarding its scientific mission, especially, those aspects related to graduate programs and scientific journals.
\end{abstract}

Keywords - Public University System (SUE), Management Indicators, Efficiency, Data Envelopment Analysis, CCR Model.
Resumen - En el año 2003 se inició el proceso de evaluación de las universidades públicas colombianas utilizando un conjunto de indicadores de gestión construidos por el Sistema de Universidades Estatales (SUE) conjuntamente con el Ministerio de Educación Nacional (MEN). Con el ánimo de conocer la eficiencia en investigación que han tenido las universidades públicas en el periodo 2003-2012 se realizó un análisis de los resultados de los indicadores utilizando el Análisis Envolvente de Datos. Se aplicó el modelo CCR orientado a los productos. A pesar de que muchas universidades han experimentado un desarrollo sostenido en algunos de los indicadores analizados y muestran niveles relativos altos de eficiencia, los resultados muestran que, en su conjunto, el Sistema Universitario Estatal tiene mucho que mejorar en su misión científica, en particular en lo relacionado con los programas de posgrado y producción de revistas.

Palabras claves - SUE, Indicadores de Gestión, Eficiencia, Análisis Envolvente de Datos, Modelo CCR. 


\section{INTRODUCTION}

The Constitution Act 30/1992, which regulates higher education in Colombia, establishes in its articles 31 and 32 the inspection and vigilance of Higher Education Institutions (IES by its acronym in Spanish) through permanent evaluations and guidelines set up by the Ministry of National Education (MEN, also by its acronym in Spanish) and the Public University System (SUE) [1]. Since 2003, SUE and MEN set out to build a management indicator system to assess resource management and goal achievement by public universities in their education, research, and extension programs missions [2]. From that moment on, SUE-MEN alliance has been designing different models to assess the results of these indicators [3]. However, models used so far do not allow identifying the deficiencies that prevent these universities from obtaining efficiency levels, in other words, they do not quantify how much, in terms of relative values, should universities improve their performance for each indicator measured in order to achieve suitable efficiency levels (i.e. maximize efficiency).

To make up for this scarcity, a research based on a method that allowed, besides analyzing universities' efficiency, identifying their failures for the indicators considered. This research, hence, had two objectives: on one hand, study efficiency level dynamics in universities for the period 2003-2012, and on the other hand, identify relative shortcomings in the aspects analyzed and the deficiency percentages that universities had in 2012, which was the last year for information procurement from the SNIES (National System for Higher Education Information). To achieve these objectives, the Data Envelopment Analysis -DEA method was adopted. The analysis was performed with the product-oriented CCR efficiency model. This paper presents the results and analysis related to scientific activity in universities exclusively. Estimations were achieved using the DEA-Solver program [4].

The analysis of scientific performance levels of public universities and the identification of their shortcomings when compared to the group of SUE universities will entitle them to correct these flaws by enforcing processes that increase and enhance their scientific activity on behalf of the Colombian society.

This paper was structured as follows: first, traditional indicators adopted by MEN to measure universities' competences, which are the inputs for DEA's model, and the indicators referred to the research activity, which are the model's outputs. Then, with the aim to compare similar universities in terms of competences and to control existing homogeneity somehow, several university groups were defined in accordance with the competence indicators that have proved more consistency during time. Next, a summary for DEA method is set forth; it includes hypotheses, concepts, and basic models enabling the proposed analysis, also, the precautions to take into account when interpreting the results obtained. Afterwards, an analysis of the efficiency values attained for each university in this period is described, as well as a detailed analysis of them for the year 2012. Finally, conclusions are stated.

\section{INDICATORS}

The underlying model to the management indicator created by SUE-MEN assumes universities as decision making units that require a great quantity of inputs in order to produce certain outputs. The model considers five groups of indicators associated to competences, education, research, extension programs, and student welfare affairs. The competence group corresponds to the inputs universities need for their performance and the other four groups are associated to output or production indicators. In this paper, only indicators oriented to research management assessment are analyzed.

Competence indicators are the following:

- Number of Full-time Professors. It is estimated based on the amount of full-time (Full professor), part-time (assistant professor), distinguished professors, or adjunct professor. To recognize adjunct professors as full professors, equivalence for each 40 teaching hours is carried out.

- Financial Resources. Comprises all the financial resources obtained by the university: State contribution, tuition fees, and extension programs.

- Management Expenses. Includes all the incurred costs for administrative staff (nonprofessors).

- Squared feet of construction. Comprehends the amount of squared feet destined by universities for teaching, research, and management (Infrastructure).

Professor, management costs, and infrastructure indicators were taken as inputs. In spite of their relevance, it was decided to exclude the financial resource indicator, since an analysis of the money values reported by MEN for the period 2003-2012 showed that many of these values do not correspond to the size of universities and are not in line with the values of the other competence indicators considered [5].

Research indicators studied (DEA's outputs) are:

- Published Papers. This indicator measures scholarly productivity through the amount of paper published in specialized journals recognized by Colciencias ${ }^{1}$. This indicator makes reference to the score awarded to the paper in terms of the classification established in the Decree 1279/2002 as follows: $\mathrm{A} 1=15, \mathrm{~A} 2=12, \mathrm{~B}=8$, and $\mathrm{C}=3$.

- Indexed Journals. Also, a score is awarded for each journal published by the university in accordance with the classification set up by the National Abstracting and Indexing System for Serial $\mathrm{Pu}$ -

\footnotetext{
1 The Administrative Department of Science, Technology and Innovation. A Colombian government agency in charge of fundamental and applied research.
} 
blications in Science, Technology and Innovation, Publindex, in which score assignment factor acknowledges intellectual production as follows: $\mathrm{A} 1=$ $15, \mathrm{~A} 2=12, \mathrm{~B}=8$ y $\mathrm{C}=3$.

- Number of Research Groups. This indicator corresponds to the number of research groups recognized and classified by Colciencias in the aforementioned period. Depending on this classification the groups are weighted with the following scores: $\mathrm{A} 1=10, \mathrm{~A}$ $=8, \mathrm{~B}=6, \mathrm{C}=4, \mathrm{D}=2$.

- Number of Masters and Doctoral Graduates. This indicator accounts for the number of Masters and Doctoral graduates. It is weighted by the Australian index, which distinguishes between education levels and the area of knowledge. This index, used in the MEN-SUE model, permits to assess, in different ways, the outputs obtained in relation to their costs; for example, the cost of educating a Specialist in Medicine is greater than that of a Master in Mathematics.

It is appropriate to clarify that the suitable weighting elements for the indicators adopted are those used in the MEN-SUE model for their yearly analyses.

\section{UnIVERSITY GROUPS}

To accomplish this research efficiency analysis, it was convenient to classify universities in six groups according to the competence indicators previously described. Cluster analysis was used, specifically, Ward's method with squared Euclidean distance using the 2012 values for the three competence indicators abovementioned. The prior classification was modified on the Professor variable to avoid extremely large groups or too many unitary groups.

In this way, three groups of universities were defined, just as shown in Table I.

Table I. University Classification Regarding their Available Competence

\begin{tabular}{|c|c|c|}
\hline \multicolumn{3}{|c|}{ COLOMBIAN PUBLIC UNIVERSITIES } \\
\hline VERY LARGE & LARGE & MEDIUM LOW \\
\hline $\begin{array}{l}\text { Antioquia } \\
\text { Nacional }\end{array}$ & $\begin{array}{l}\text { Cauca } \\
\text { UPTC } \\
\text { UIS } \\
\text { Valle } \\
\text { Distrital }\end{array}$ & $\begin{array}{l}\text { Surcolombiana } \\
\text { Córdoba } \\
\text { Magdalena } \\
\text { Militar } \\
\text { Cundinamarca } \\
\text { Quindío }\end{array}$ \\
\hline MEDIUM & SMALL & VERY SMALL \\
\hline $\begin{array}{l}\text { Cartagena } \\
\text { Caldas } \\
\text { Pedagógica } \\
\text { Tolima } \\
\text { Pereira } \\
\text { Pamplona } \\
\text { Atlántico }\end{array}$ & $\begin{array}{l}\text { Sucre } \\
\text { Llanos } \\
\text { Guajira } \\
\text { Popular } \\
\text { Nariño } \\
\text { Cúcuta } \\
\text { Colegio }\end{array}$ & $\begin{array}{l}\text { Pacífico } \\
\text { Ocaña }\end{array}$ \\
\hline
\end{tabular}

Source: Authors

\section{DATA ENVELOPMENT ANALYSIS (DEA)}

Data Envelopment Analysis (DEA) is a non-parametric deterministic method to assess the relative efficiency of a homogeneous group of productive units identified as decision units (DU). Through linear programming techniques, and based on the observed input and output values, an efficiency frontier is established to assess the efficiency of the units studied. This frontier is comprised of efficient units and, as its name states, "envelops" or limits those which are not. This group of efficient universities constitutes the reference groups for each non-efficient university. a university's efficiency measurement is given in terms of its distance to this frontier. In this way, DEA answers the question of how to measure relative efficiency by identifying the most efficient unit and proposing improvements, both for the inputs and the outputs, for the units that are not in this frontier comparing them to an efficient reference group [4], [6].

DEA's method has, as every model, advantages and disadvantages. Regarding the first, the method typifies each decision unit with a unique technical efficiency score, which, in turn, is relative. Furthermore, it estimates the improvements required by an inefficient unit (increasing the outputs or decreasing the inputs) in order to become efficient. This procedure is executed by identifying an efficient unit, real or unreal (linear combination of efficient units), in the efficiency frontier that identifies with the deficient unit, for example, it can have the same amount of inputs but more outputs. Precisely, those production values of the efficient reference unit constitute the goal to be reached by the inefficient unit. Likewise, as a non-parametric method, estimation of efficiencies is achieved without assuming any functional relationship between inputs and outputs.

Additionally, DEA's method allows managing variables of different measurement values, as it is the case of universities' inputs and products.

Among this method's disadvantages is the availability of a high number of efficient units, which is a consequence of its flexibility for entitling every of those units weight in different way the inputs and the outputs in the search for the maximum efficiency. To avoid this problem it is recommended not to include many variables in the model. The researcher, then, must be very careful when selecting the variables to be included: not excluding relevant variables, or the opposite, including irrelevant ones.

Due to its deterministic nature, it hinders from explaining random-based effects as inefficiencies in a unit. It neither allows identifying the strange units (outliers) within the productive process under analysis. 
Finally, and to keep it in mind, this method measures relative efficiency, this means that regarding the rest of the units, it is not an ideal output measurement. Then, in such case, it is possible to prove the existence of efficient universities within the SUE. Nonetheless, if they are compared to, for example, private universities, efficiency values may vary.

DEA has been used to assess efficiency both in basic education and higher education institutions [7]-[10]; to compare efficiency of universities around the world [11]-[17]; to compare the efficiency levels in different departments of a same university or the same department in different universities [18]-[24]; to assess aspects such as research and education efficiency of higher education institutions, scholarly production, and research groups' performance, among others [25]-[30]. In particular, [26] Colombian public universities performance is analyzed.

In DEA's method with $N$ decision units, $m$ inputs, and $s$ products, the efficiency measurement is assumed as the ratio between the production in regard to the inputs required for that output. As this concerns several inputs and outputs, it is necessary to combine them in such way that they produce the maximum efficiency, this means, solving the fractional problem hereunder (1):

$$
\max _{u, v} \theta=\frac{\sum_{r=1}^{s} u_{r} y_{r o}}{\sum_{i=1}^{m} v_{i} x_{i o}}
$$

Subject to (2) and (3):

$$
\begin{aligned}
& \frac{u_{1} y_{1 j}+u_{2} y_{2 j}+\ldots+u_{s} y_{s j}}{v_{1} x_{1 j}+v_{2} x_{2 j}+\ldots+v_{m} x_{m j}} \leq 1 j=1, \ldots, N \\
& u_{1}, u_{2}, \ldots, u_{s} \geq 0 \\
& v_{1}, v_{2}, \ldots, v_{m} \geq 0 \\
& x_{i}: \text { cantidad del insumo } i, i=1,2, \ldots, m \\
& y_{r}: \text { cantidad del producto } r, r=1,2, \ldots, s
\end{aligned}
$$

The equations (1)-(3) are known as the DEACCR method, for the decision unit $D U_{0}$ when there are $N$ decision units: $D U_{1}, D U_{2}, \ldots, D U_{N} m$ types of inputs $x$, and $s$ different products $y$. The objective is to maximize efficiency measurement by finding the best weighting set for the input $\left(v_{i}, i=1, \ldots, m\right)$ and for the outputs $\left(u_{r}, r=1, \ldots, s\right)$ in each unit.

The abovementioned method describes the basic features of DEA and of the efficiency measurement it generates:

- For each DU, the DEA-CCR method creates virtual inputs and outputs, in the sense that from the data (inputs and outputs) provided by the units, the method selects the best weight set $\left(v_{i}^{*}\right), i=1,2, \ldots m y\left(u_{r}^{*}\right), r=1,2, \ldots s$ to be assigned to input and output, respectively, in order to enhance performance. Due to weight set variation in each unit, $n$ different models are available, one for each decision unit. DEA settles the discussion around the relevance of input or the selected products by weighting them in such way that the greatest amount of products is achieved as a response of the best input combination.

- Equations (2) and (3) indicate that weighting is not previously defined, on the contrary, they depend on the values observed in all the DUs considered and they are estimated so as to obtain the maximum efficiency value.

- Restriction (3) means that the proportion of virtual output/virtual input should not exceed 1 for each of the DU, including the one being assessed, because of this, the maximum possible efficiency value for any decision unit is . In other words, this restriction fixes in 1 the maximum relation between the products generated in regard to the inputs used in all the decision units. Weights are estimated for each $\mathrm{Du}$ in such way that there is no other DU that, with the same weighting, surpasses the value 1 .

- A DU must obtain an efficiency value of 1 to be considered efficient.

- The subscript indicates that weighting for input and products are typical of each DU, for this reason, there are as many CCR models as there are DUs under consideration.

- DEA is a non-parametric method since it does not specify beforehand any functional form for the efficiency frontier; it is not statistic because it does not presuppose a probabilistic distribution for the unexplained efficiency.

Weighting flexibility avoids any subjective judgments regarding the relative importance of each variable when determining a DU's efficiency, which in the present case of universities would represent a difficult to agree on and wearing task. As it is common in reality, advantages are also often disadvantages: the program can assign a null or scarce weight to a specific factor that, from the theoretic point of view, has a major importance in the relative efficiency of DUs [4]. To prevent this situation, the model should be corrected by demanding that the coefficients to be estimated are strictly positive or belong to a determined interval.

The fractional problem defined in (1)-(3) has infinite solutions [if $(u, v)$ is a solution, then $(a u, a v)$ is also a solution for any $a$ ] and, additionally, it is not a linear model. To correct these pitfalls, a linear programming problem with a unique solution is generated, as seen in (4) to (8):

$\max _{u, v} \theta=u_{1} y_{1 o}+\cdots+u_{s} y_{s o}$

Subject to: 


$$
\begin{aligned}
& v_{1} x_{1 o}+\cdots+v_{m} x_{m o}=1 \\
& u_{1} y_{1 j}+\cdots+u_{s} y_{s j} \leq v_{1} x_{1 j}+\cdots+v_{m} x_{m j} \\
& \quad(j=1,2, \ldots, n) \\
& v_{1}, v_{2}, \ldots, v_{m} \geq 0 \\
& u_{1}, u_{2}, \ldots, u_{s} \geq 0
\end{aligned}
$$

In this model, a DU is considered CCR - efficient if $\theta^{*}{ }_{o}=1$ and there is, at least, one optimum $\left(u^{*}, v^{*}\right)$ with $u^{*}>0$ and $v^{*}>0$ where $u^{*}$ and $v^{*}$ are the vectors conformed by the product and input weights, respectively; otherwise, it is inefficient. Hence, if a DU is CCR - inefficient, then $\theta^{*}<1$ for an optimum $\left(u^{*}, v^{*}\right)$ so, it can be concluded that there should be at least one DU satisfying the equality in (9):

$$
\sum_{r=1}^{s} u_{r}^{*} y_{r j}=\sum_{i=1}^{m} v_{i}^{*} x_{i j}
$$

In other words, there is another DU that reaches an efficiency level of 1 with the same weighting elements that allow the studied unit to achieve its maximum value, this means there is another unit with higher efficiency than the one analyzed when equally weighting the inputs and outputs.

There is a dual model for to the inputs and other for the products associated to the linear programming model defined in equations (4) to (8). Except for administrative expenses, it is pointless to reduce the other inputs considered in this study (number of professors and squared feet of construction), so the dual model for products is used. The dual model, called enveloping, is, for operational purposes, the most used in empirical studies.

The output-oriented dual model for the linear programming problem previously defined is expressed in (10) - (13):

$$
\left(P D_{o}\right) \operatorname{máx} \phi
$$$$
\phi, \lambda
$$

Subject to

$$
\begin{array}{ll}
\phi y_{r o} \leq \sum_{j=1}^{n} \lambda_{j} y_{r j} & (r=1,2, \ldots, s) \\
\sum_{j=1}^{n} \lambda_{j} x_{i j} \leq x_{i o} & (i=1,2, \ldots, m) \\
\lambda_{j} \geq 0 &
\end{array}
$$

Where

$\emptyset_{\circ}$ : Parameter used to construct the assessed unit's efficiency.

$\lambda_{j}$ : Weighting obtained as solution to the program. Expresses the weight that each DU has within the comparison group of the $D U_{o}$.
This model compares $D U_{o}$ with all real and unreal DUs that produce the same or more and that consume less or the same than the $D U_{o}$.

So, if $\emptyset_{o}$ is equal to 1 , the $D U_{o}$ will be efficient, since the program will have searched among the real and unreal DUs that produce the same quantity or more, and use the same or more amount of input.

This model aims at maximizing production without modifying the number of input currently used. Slacks $\delta^{-*}, \delta^{+*}$ are defined in (14), which are associated to the optimum value, as well as the non-negative differences from (11) and (12):

$$
\delta^{-^{*}}=Y \lambda-\phi y_{0} \quad \delta^{+^{*}}=x-\lambda X
$$

Slacks $\delta^{-*}, \delta^{+*}$ make reference to product excess and input deficit, respectively, in regard to the frontier constituted by some of the remaining decision units.

Optimum solution for the product-oriented dual model, equations (10) to (13), will be $\left(\emptyset^{*}, \lambda^{*}\right.$, $\left.\delta^{-*}, \delta^{+*}\right)$ where $\emptyset^{*}>1$; if a DU has the $\emptyset^{*}=1$ value and the slack values are zero $\left(\delta^{* *}=0, \delta^{*^{*}}=0\right)$, then, such DU is technically efficient, otherwise, inefficient.

Inefficient units project over the efficient frontier, the projection point being an efficient real or virtual unit obtained as a linear convex combination of efficient units. The units participating in the definition of an inefficient unit projection constitute the reference group. The amount of times an efficient institution appears in a reference group is related to its efficiency level: if it augments, the conviction of it being an efficient unit grows. On the contrary, if it only appears a few times, it can indicate that it has a particular feature which makes it inadequate to be reference of others.

\section{Analysis of Results}

To use DEA's method in order to measure and compare the efficiency of organizational units, the DEA-Solver Learning 3.0 was used. The efficiency analysis is presented in two sections: the first, on one hand, presents the results of relative efficiency in every year of the period 2003-2012, and on the other, analyzes universities dynamics; the second, studies in detail efficiency levels in 2012 and university slacks are estimated for each indicator measured.

\section{A. Efficiency 2003-2012}

The relative nature of DEA's model in regard to the observed values in the inputs and outputs make that efficiency levels for different years may 
not be directly compared among them. However, they are a measurement of the relative position that universities have in the overall system. For instance, if a university A reached an efficiency of 0.6 in the year 2005 and then, in 2006, a 0.8 , it can be said that its efficiency increased in comparison to the other universities, even if their products do not reflect any improvement in the two years studied.

Universities that have efficiency levels below 1 are considered inefficient, but it they obtain a value of 1 , they are technically efficient. There are universities with a null efficiency value in some years because the values in all the variables analyzed were null. These universities are: Pacífico (2003-2007), Ocaña (2003-2008), Guajira (2003 and 2005), Amazonas (2003), Popular (2003), Cundinamarca (2003 and 2004) and UNAD (2003). On the other hand, Militar and Pedagógica universities are the only ones that have managed to be efficient during the whole period. Most of the inefficient universities concentrate in the Small group, where only Sucre was efficient (2009). Antioquia and Nacional, Very Large universities, are efficient during most of the period, except in 2011 and 2003, respectively.

Next, a brief analysis of universities' dynamics regarding efficiency for this period is put forward. The analysis is carried through by university groups.

\section{1) Very Small Universities (VS)}

Universidad del Pacífico, after a null behavior in the first five years, starts an ascending process that makes it be considered as efficient for the years 2010 and 2011, however, in 2012, though with a high value, it becomes inefficient again (Fig. 1).

Very Small Universities 2003 - 2012

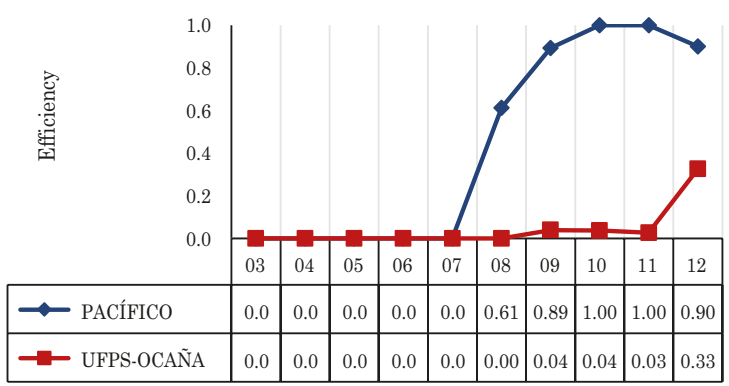

Fig. 1. Efficiency of Very Small Universities, Period 2003-2012. Source: Authors

As it will be seen later, this efficiency was attained due to the number of research groups ex- clusively; the remaining variables studied are still in null levels. Universidad Francisco de Paula de Santander, Ocaña branch, contrarily, presents almost null efficiency levels during the overall period; only in 2012 , reaches a value, although deficient, much higher than the rest of the years.

\section{2) Small Universities (S)}

Fig. 2 illustrates that universities from this group expound a moderate growing trend in the years analyzed.

Sucre, the only university that managed to be efficient in the year 2009, in the subsequent years exhibits a steep decline although, in 2012, recovers a little; Chocó, reached 0.82 in 2006 , but afterwards, results fluctuate between 0.35 and 0.73 , with an average value of 0.51 for the entire period.

Before 2012, Guajira, Amazonas, Llanos, Popular, and UFPS Cúcuta show very low efficiency level values, however, in 2012 they demonstrate a marked upturn.

Nariño, although until 2009 presented low values, managed to recover in the last three years, particularly in 2012, when it reached a value of 0.88 .

Small Universities 2003 - 2012

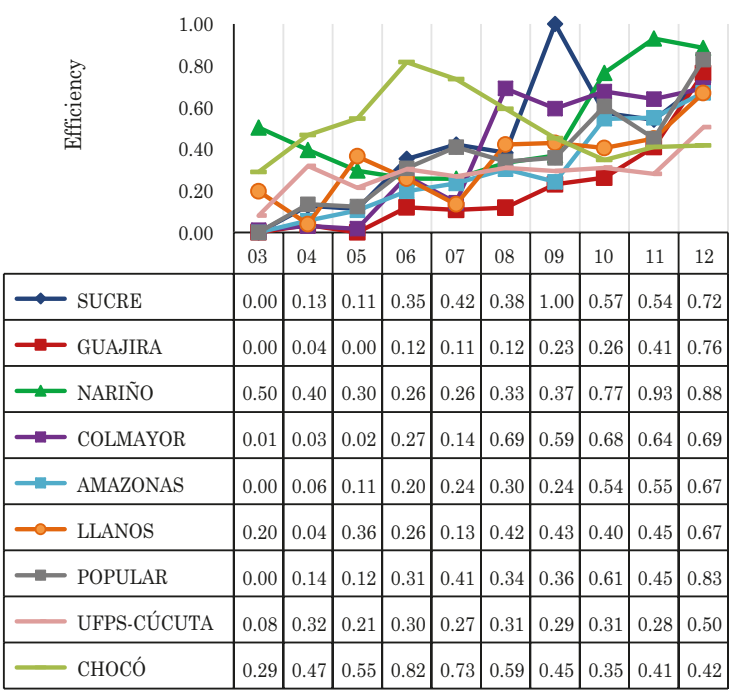

Fig. 2. Efficiency of Small Universities, Period 2003-2012. Source: Authors

In the case of Colegio Mayor de Cundinamarca, two main periods can be identified: for the first five years (2003-2007), its efficiency level did not surpass 0.27 (average $=0.1$ ), but in the last five (2008-2012), it was between 0.59 and 0.69 (average $=0.68)$ as a consequence of research group increase and the creation of some journals. 


\section{3) Medium Low Universities (ML)}

Just as it is evidenced in Fig. 3, Universidad Militar stands out in this group as the most efficient; it was efficient in the years 2003-2011, and it only had a drawback in 2012 .

Medium Low Universities 2003 - 2012

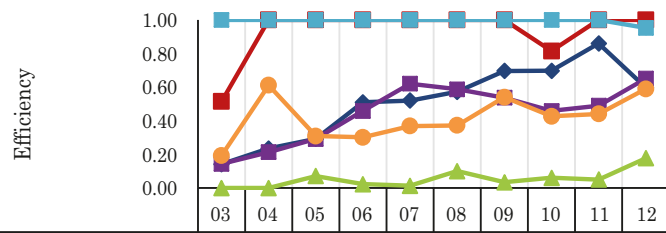

\begin{tabular}{|l|l|l|l|l|l|l|l|l|l|l|}
\hline$\multimap$ SURCOLOMBIANA & 0.14 & 0.23 & 0.29 & 0.51 & 0.52 & 0.57 & 0.70 & 0.70 & 0.86 & 0.60
\end{tabular}

\begin{tabular}{|l|l|l|l|l|l|l|l|l|l|l|}
\hline- MAGDALENA & 0.51 & 1.00 & 1.00 & 1.00 & 1.00 & 1.00 & 1.00 & 0.82 & 1.00 & 1.00 \\
\hline$\rightarrow-$ CUNDINAMARCA & 0.00 & 0.00 & 0.07 & 0.02 & 0.01 & 0.10 & 0.03 & 0.06 & 0.05 & 0.18 \\
\hline$\rightarrow$ CÓRDOBA & 0.14 & 0.21 & 0.29 & 0.46 & 0.62 & 0.59 & 0.54 & 0.46 & 0.49 & 0.65 \\
\hline- MILITAR & 1.00 & 1.00 & 1.00 & 1.00 & 1.00 & 1.00 & 1.00 & 1.00 & 1.00 & 0.95 \\
\hline$\longrightarrow$ QUINDÍO & 0.19 & 0.61 & 0.31 & 0.30 & 0.37 & 0.37 & 0.54 & 0.43 & 0.44 & 0.59 \\
\hline
\end{tabular}

Fig. 3. Efficiency of Medium Low Universities, Period 2003-2012. Source: Authors

Magdalena also stands out; for 6 consecutive years (2004-2009), it reached the highest efficiency value, and despite it decreased in 2010, it was recovered in 2011 and 2012. To hightlight, Surcolombiana's behavior, which, in spite of not being efficient ever before, shows a sustained and positive development in time until 2011; nonetheless, in 2012 it returned to the levels obtained in 2008.

Quindío and Córdoba also manifest a growing trend reaching the highest values in 2012; however, they are not relevant yet. Universidad de Cundinamarca always delivers very low efficiency levels.

\section{4) Medium Universities (M)}

As illustrated in Fig. 4, in this group Pedagógica and Pereira stand out. The former, despite its peaks and troughs, has been considered efficient in the years analyzed; and the latter always kept its efficiency level, with the exception of 2010 when it was very close to being efficient (0.99).

With ups and downs, Atlántico achieved efficiency for two periods of consecutive years: 2006 2007 and 2010-2012. Caldas managed to be efficient in the last four years: 2009-2012. For its part, Cartagena, as a consequence of a growing trend, achieves efficiency in 2010 and 2011; in 2012 attains a value of 0.89 .
The remaining universities, Tolima, Pamplona, and UNAD, have demonstrated rather low efficiency levels during the overall period, particularly UNAD which, with a growing tendency, obtains in 2012 the highest value (0.53).

\section{Medium Universities 2003 - 2012}

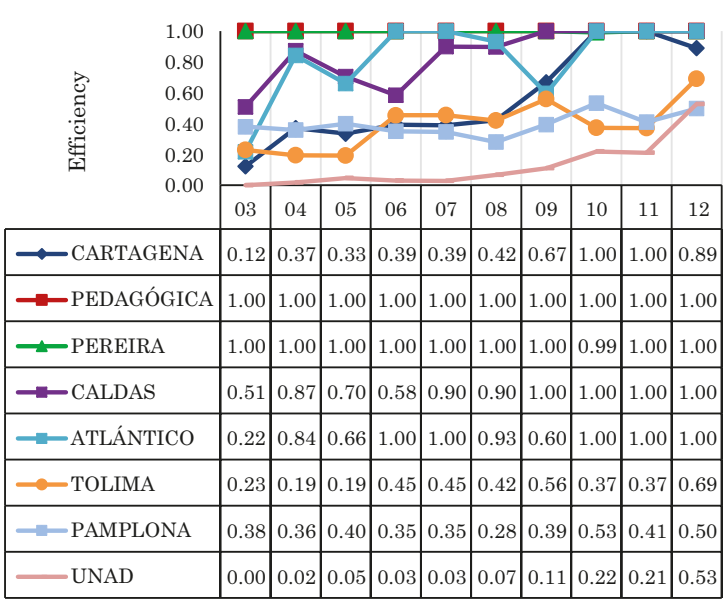

Fig. 4. Efficiency of Medium Universities, Period 2003-2012. Source: Authors

\section{5) Large Universities (L)}

Fig. 5 points out Valle as the university with the best performance in this group throughout the period studied, except for 2011; in the rest of the years it achieved efficiency. Cauca and UIS' behavior, although efficient (Cauca in 2003, 2005, 2008, and 2009; UIS in 2003, 2004, and 2009), has evidenced a decreasing trend, obtaining in 2012, 0.69 and 0.67, respectively.

Large Universities003 - 2012

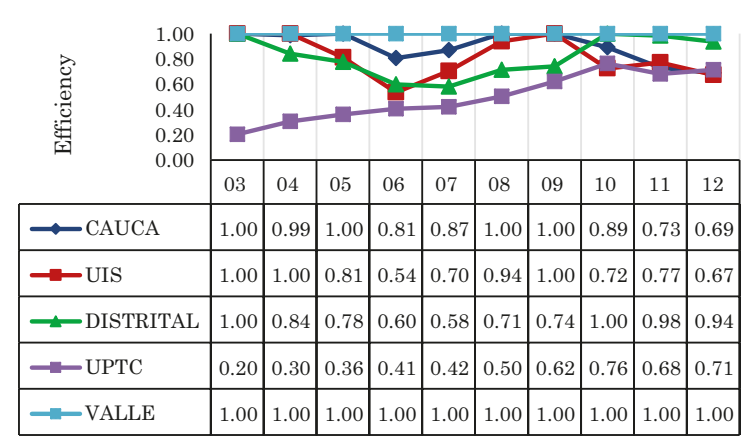

Fig. 5. Efficiency of Large Universities, Period 2003-2012. Source: Authors 
Distrital's behavior has two different periods: after being efficient in 2003, started a decreasing trend until 2007 when it managed to revert the process to become efficient again in 2010; afterwards, it has been very close to being.

UPTC, with fairly low levels during the first years, has the merit of presenting a sustained growth until 2010, when it passed from 0.2 in 2003 to 0.76 in 2010 , and maintaining close values the next two years.

6) Very Large Universities (VL)

While Antioquia achieves efficiency during the complete period, Nacional accomplishes it after 2003 (Fig. 6).

Very Large Universities 2003 - 2012

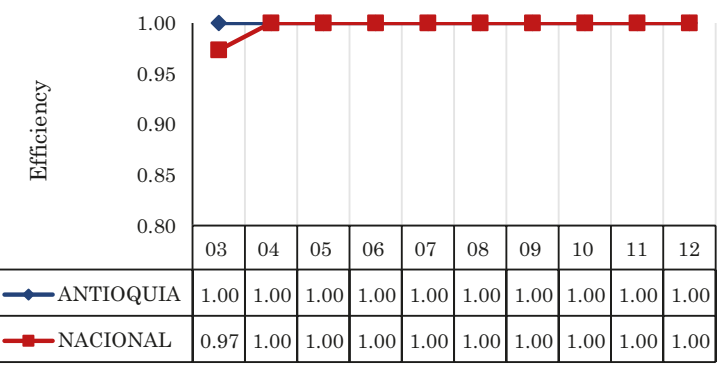

Fig. 6. Efficiency of Very Large Universities, Period 2003-2012. Source: Authors

\section{B. Analysis Year 2012}

University efficiency for the year 2012, in descending order, can be observed in Table II. In this case, values are presented as percentages.

Efficiency values from Table II have an average of $75 \%$ and a coefficient of variation of $45 \%$, indicating the high homogeneity that in terms of research exists in SUE. Given the efficiency levels reached by universities in 2012, universities can be classified in four groups:

1. Eight efficient universities: Pedagógica, Nacional, Magdalena, Caldas, Antioquia, Tecnológica de Pereira, Atlántico, and Valle.

2. Six universities that, without being efficient, achieved high efficiency levels (between 0.80 and 0.95): Militar, Distrital, Pacífico, Cartagena, Nariño, and Popular del Cesar.

3. Eleven universities with a medium level of research efficiency (values between 0.60 and 0.80): Guajira, Sucre, UPTC, Colegio Mayor, Tolima, Cauca, UIS, Amazonas, Llanos, Córdoba, and Surcolombiana.

4. Seven universities with low research efficiency levels (values less than 0.60): Quindío, UNAD, UFPS Cúcuta, Pamplona, Chocó, UFPS Ocaña, and Cundinamarca.
Table II. Efficiency 2012

\begin{tabular}{|c|c|}
\hline $\begin{array}{l}\text { HIGHER EDUCATION } \\
\text { INSTITUTIONS }\end{array}$ & EFFICIENCY (\%) \\
\hline PEDAGÓGICA & 100 \\
\hline NACIONAL & 100 \\
\hline MAGDALENA & 100 \\
\hline CALDAS & 100 \\
\hline ANTIOQUIA & 100 \\
\hline PEREIRA & 100 \\
\hline ATLÁNTICO & 100 \\
\hline VALLE & 100 \\
\hline MILITAR & 95 \\
\hline DISTRITAL & 94 \\
\hline PACÍFICO & 90 \\
\hline CARTA & 89 \\
\hline NARIÑO & 88 \\
\hline POPULAR & 83 \\
\hline GUAJIRA & 76 \\
\hline SUCRE & 72 \\
\hline UPTC & 71 \\
\hline COLEGIO MAYOR & 69 \\
\hline TOLIMA & 69 \\
\hline CAUCA & 69 \\
\hline UIS & 67 \\
\hline AMAZONAS & 67 \\
\hline LLANOS & 67 \\
\hline CÓRDOBA & 65 \\
\hline SURCOLOMBIANA & 60 \\
\hline QUINDÍO & 59 \\
\hline UNAD & 53 \\
\hline CÚCUTA & 50 \\
\hline PAMPLONA & 50 \\
\hline CHOCÓ & 42 \\
\hline UFPS-OCAÑA & 33 \\
\hline CUNDINAMARCA & 18 \\
\hline
\end{tabular}

Results show that none of the Very Small or Small universities managed to be efficient. From the group of Medium Low universities, only Magdalena accomplished this. In the group of the Medium universities, efficiency was achieved by Pedagógica, Caldas, Pereira, and Atlántico. Among the Large university group, only Universidad del Valle can be considered efficient, and finally, for the Very Large group, both Nacional and Antioquia, accomplished efficiency. 
Table III. Research Index 2012: Values Observed, Intended Values and Deficiency or Surplus Percentages

\begin{tabular}{|c|c|c|c|c|c|c|c|c|c|c|c|c|c|c|c|c|}
\hline \multirow{3}{*}{ HEI } & \multicolumn{16}{|c|}{ VALUES OBSERVED VS OBJECTIVE VALUES RESEARCH INDEX } \\
\hline & \multicolumn{4}{|c|}{ RESEARCH GROUPS } & \multicolumn{4}{|c|}{ JOURNALS } & \multicolumn{4}{|c|}{ PAPERS } & \multicolumn{4}{|c|}{ M-D GRADUATES } \\
\hline & OBS & INT & & $\%$ & OBS & INT & & $\%$ & OBS & INT & & $\%$ & OBS & INT & & $\%$ \\
\hline PACÍFICO & 10 & 11 & & 11 & 0 & 10 & & . & 0 & 183 & & . & 0 & 45 & & . \\
\hline UFPS-OCAÑA & 5 & 15 & & 207 & 0 & 5 & & . & 12 & 224 & & 1770 & 0 & 17 & & . \\
\hline SUCRE & 19 & 26 & & 39 & 3 & 6 & & 109 & 305 & 423 & & 39 & 0 & 22 & & . \\
\hline GUAJIRA & 26 & 34 & & 31 & 0 & 32 & & . & 42 & 405 & & 864 & 0 & 153 & & . \\
\hline NARIÑO & 57 & 64 & & 13 & 20 & 23 & & 13 & 935 & 1057 & & 13 & 49 & 55 & & 13 \\
\hline COLEGIO MAYOR & 29 & 42 & & 45 & 20 & 29 & & 45 & 145 & 618 & & 326 & 0 & 39 & & $\cdot$ \\
\hline AMAZONAS & 31 & 46 & & 49 & 6 & 9 & & 49 & 215 & 369 & & 72 & 39 & 58 & & 49 \\
\hline LLANOS & 34 & 51 & & 50 & 15 & 22 & & 50 & 402 & 851 & & 112 & 2 & 61 & & 2952 \\
\hline POPULAR & 38 & 46 & & 21 & 0 & 7 & & . & 72 & 257 & & 257 & 0 & 19 & & . \\
\hline UFPS-CÚCUTA & 22 & 44 & & 98 & 3 & 54 & & 1702 & 445 & 883 & & 98 & 14 & 117 & & 738 \\
\hline CHOCÓ & 23 & 55 & & 140 & 6 & 39 & & 548 & 67 & 1452 & & 2080 & 3 & 172 & & 5645 \\
\hline SURCOLOMBIANA & 37 & 62 & & 68 & 12 & 27 & & 121 & 108 & 659 & & 511 & 27 & 115 & & 325 \\
\hline MAGDALENA & 72 & 41 & $+*$ & 76 & 9 & 38 & & 326 & 694 & 460 & + & 51 & 25 & 186 & & 645 \\
\hline CUNDINAMARCA & 14 & 79 & & 465 & 0 & 14 & & . & 38 & 506 & & 1231 & 0 & 44 & & . \\
\hline CÓRDOBA & 51 & 78 & & 54 & 18 & 33 & & 84 & 622 & 1065 & & 71 & 2 & 139 & & 6862 \\
\hline MILITAR & 55 & 58 & & 5 & 78 & 82 & & 5 & 1360 & 1427 & & 5 & 61 & 100 & & 64 \\
\hline QUINDÍO & 44 & 75 & & 70 & 3 & 42 & & 1302 & 826 & 1401 & & 70 & 21 & 96 & & 358 \\
\hline CARTAGENA & 112 & 126 & & 12 & 9 & 52 & & 480 & 2158 & 2854 & & 32 & 19 & 204 & & 975 \\
\hline PEDAGÓGICA & 66 & 35 & + & 87 & 62 & 17 & + & 269 & 743 & 745 & & 0 & 301 & 82 & + & 269 \\
\hline PEREIRA & 98 & 87 & + & 12 & 11 & 48 & & 336 & 1504 & 1339 & + & 12 & 242 & 216 & + & 12 \\
\hline CALDAS & 59 & 63 & & 6 & 108 & 86 & + & 25 & 1816 & 1559 & + & 16 & 96 & 77 & + & 25 \\
\hline ATLÁNTICO & 94 & 90 & + & 4 & 14 & 17 & & 22 & 436 & 1180 & & 171 & 41 & 57 & & 39 \\
\hline TOLIMA & 54 & 78 & & 45 & 9 & 29 & & 223 & 988 & 1785 & & 81 & 140 & 203 & & 45 \\
\hline PAMPLONA & 43 & 86 & & 101 & 15 & 54 & & 262 & 641 & 1287 & & 101 & 49 & 98 & & 101 \\
\hline UNAD & 68 & 129 & & 90 & 6 & 85 & & 1314 & 154 & 1249 & & 711 & 0 & 399 & & \\
\hline CAUCA & 98 & 142 & & 45 & 12 & 36 & & 200 & 1410 & 2050 & & 45 & 30 & 129 & & 330 \\
\hline UIS & 88 & 131 & & 48 & 98 & 145 & & 48 & 2539 & 4220 & & 66 & 167 & 265 & & 59 \\
\hline DISTRITAL & 116 & 124 & & 7 & 52 & 90 & & 73 & 1529 & 1631 & & 7 & 78 & 382 & & 390 \\
\hline UPTC & 127 & 178 & & 40 & 48 & 67 & & 40 & 1156 & 1619 & & 40 & 142 & 199 & & 40 \\
\hline VALLE & 185 & 179 & + & 3 & 94 & 215 & & 129 & 5828 & 5651 & + & 3 & 364 & 353 & + & 3 \\
\hline ANTIOQUIA & 245 & 213 & + & 15 & 230 & 251 & & 9 & 7442 & 6455 & + & 15 & 317 & 479 & & 51 \\
\hline NACIONAL & 689 & 387 & + & 78 & 402 & 237 & + & 70 & 23517 & 11480 & + & 105 & 1638 & 800 & + & 105 \\
\hline
\end{tabular}

*: +: Indicates a surplus percentage

Source: Authors

\section{Indicators: Observed Values vs Intended Values and Slack Percentages}

Table III shows universities in an ascending order according to their competences and the following information from the four indicators considered: the values observed in 2012, the intended values that each of them should reach while keeping their input fixed in order to become technically efficient, and the percentage of improvement so as to achieve effi- ciency. The percentage preceded by a plus sign (+) indicates that the university exceeded the objective, for example, Universidad Nacional exceeded the intended values for each indicator, it reached a $78 \%$ more in the Research Group score, a 70\% in Journals, and in Papers and Masters and Doctoral Graduates (MDG) a $105 \%$ more.

Improvement percentages without a value belong to the universities whose observed values were zero, this is, they had a null value in the indicator; 
it makes impossible to estimate their improvement in relative terms, however, the intended value shows what they should achieve. For example Universidad Guajira, that does not have any journal, should have 32 points to be considered efficient in this aspect.

On the other hand, the most inefficient from the system, Universidad de Cundinamarca, should produce, according to its competence, 65 points for research groups, 14 points for Journals, 468 points for papers, and 44 points for MDG in order to be considered efficient in all the indicators. These improvement implies increasing in almost 5 times the amount of research groups that it had in 2012, publish journals (zero journals were reported in 2012), improve in 5 times paper production, and create Masters and Doctoral programs (in 2012 no MDG were reported).

Data obtained reveal that research performance is related to the size of the university. It is observed, for example, low production values in Very Small and Small universities for 2012. These values increased meaningfully in the group of Medium Low universities and it keeps ascending until they reach the Very Large group. In particular, it is important to point out the low values obtained by the UNAD in regard to the rest of the universities of the same group, this is Medium universities; this aspect highlights its nature for basically educating professionals.

Table IV shows the universities and the indicator in which they achieve their objectives. If the university managed to surpass the intended value, it is identified with the symbol ü; on the contrary, if values were below, it will be marked with an X.

Universities from Very Small and Small groups are below the intended values in every indicator.

In the Medium Low group, only Universidad del Magdalena managed to surpass intended values, in this case, with the Research Groups and Papers indicators.

Cartagena, Tolima, Pamplona, and UNAD, in the Medium group, were inefficient in all the indicators, whereas Pedagógica was inefficient only in Papers, Tecnológica de Pereira in Journals, and Caldas in Research Groups.

Within the Large university group, only Valle accomplished efficiency in some indicators: Research Groups, Papers, and MDG; it still needs to improve in Journals, so it should create as much journals as it already has. The remaining universities from this group were inefficient in all the indicators.

For the Very Large group, Nacional was efficient in all the indicators, while Universidad de Antioquia was efficient in Research Groups and Paper publication, so it ought to improve in Journals and MDG.

To sum up, it can be said that from all the universities in the SUE, only Universidad Nacional achieved the intended values for all the research indicators in 2012. The universities that exceeded
Table IV. Research Indicators Obtained In 2012

\begin{tabular}{|c|c|c|c|c|}
\hline \multirow{2}{*}{ HEI } & \multicolumn{4}{|c|}{ EFFICIENT } \\
\hline & GROUPS & JOURNALS & PAPERS & MDG \\
\hline PACÍFICO & $\mathrm{X}$ & $\mathrm{X}$ & $\mathrm{X}$ & $\mathrm{X}$ \\
\hline UFPS-OCAÑA & $\mathrm{X}$ & $\mathrm{X}$ & $\mathrm{X}$ & $\mathrm{X}$ \\
\hline SUCRE & $\mathrm{X}$ & $\mathrm{X}$ & $\mathrm{X}$ & $\mathrm{X}$ \\
\hline GUAJIRA & $\mathrm{X}$ & $\mathrm{X}$ & $\mathrm{X}$ & $\mathrm{X}$ \\
\hline NARIÑO & $\mathrm{X}$ & $\mathrm{X}$ & $\mathrm{X}$ & $\mathrm{X}$ \\
\hline COLMAYOR & $\mathrm{X}$ & $\mathrm{X}$ & $\mathrm{X}$ & $\mathrm{X}$ \\
\hline AMAZONAS & $\mathrm{X}$ & $\mathrm{X}$ & $\mathrm{X}$ & $\mathrm{X}$ \\
\hline LLANOS & $\mathrm{X}$ & $\mathrm{X}$ & $\mathrm{X}$ & $\mathrm{X}$ \\
\hline POPULAR & $\mathrm{X}$ & $\mathrm{X}$ & $\mathrm{X}$ & $\mathrm{X}$ \\
\hline UFPS-CÚCUTA & $\mathrm{X}$ & $\mathrm{X}$ & $\mathrm{X}$ & $\mathrm{X}$ \\
\hline CHOCÓ & $\mathrm{X}$ & $\mathrm{X}$ & $\mathrm{X}$ & $\mathrm{X}$ \\
\hline SURCOLOMBIANA & $\mathrm{X}$ & $\mathrm{X}$ & $\mathrm{X}$ & $\mathrm{X}$ \\
\hline MAGDALENA & $\ddot{u}$ & $\mathrm{X}$ & $\ddot{u}$ & $\mathrm{X}$ \\
\hline CUNDINAMARCA & $\mathrm{X}$ & $\mathrm{X}$ & $\mathrm{X}$ & $\mathrm{X}$ \\
\hline CÓRDOBA & $\mathrm{X}$ & $\mathrm{X}$ & $\mathrm{X}$ & $\mathrm{X}$ \\
\hline MILITAR & $\mathrm{X}$ & $\mathrm{X}$ & $\mathrm{X}$ & $\mathrm{X}$ \\
\hline QUINDÍO & $\mathrm{X}$ & $\mathrm{X}$ & $\mathrm{X}$ & $\mathrm{X}$ \\
\hline CARTAGENA & $\mathrm{X}$ & $\mathrm{X}$ & $\mathrm{X}$ & $\mathrm{X}$ \\
\hline PEDAGÓGICA & $\ddot{\mathrm{u}}$ & $\ddot{\mathrm{u}}$ & $\mathrm{X}$ & $\ddot{\mathrm{u}}$ \\
\hline PEREIRA & $\ddot{u}$ & $\mathrm{X}$ & $\ddot{\mathrm{u}}$ & $\ddot{u}$ \\
\hline CALDAS & $\mathrm{X}$ & $\ddot{\mathrm{u}}$ & $\ddot{\mathrm{u}}$ & $\ddot{\mathrm{u}}$ \\
\hline ATLÁNTICO & $\ddot{\mathrm{u}}$ & $\mathrm{X}$ & $\mathrm{X}$ & $\mathrm{X}$ \\
\hline TOLIMA & $\mathrm{X}$ & $\mathrm{X}$ & $\mathrm{X}$ & $\mathrm{X}$ \\
\hline PAMPLONA & $\mathrm{X}$ & $\mathrm{X}$ & $\mathrm{X}$ & $\mathrm{X}$ \\
\hline UNAD & $\mathrm{X}$ & $\mathrm{X}$ & $\mathrm{X}$ & $\mathrm{X}$ \\
\hline CAUCA & $\mathrm{X}$ & $\mathrm{X}$ & $\mathrm{X}$ & $\mathrm{X}$ \\
\hline UIS & $\mathrm{X}$ & $\mathrm{X}$ & $\mathrm{X}$ & $\mathrm{X}$ \\
\hline DISTRITAL & $\mathrm{X}$ & $\mathrm{X}$ & $\mathrm{X}$ & $\mathrm{X}$ \\
\hline UPTC & $\mathrm{X}$ & $\mathrm{X}$ & $\mathrm{X}$ & $\mathrm{X}$ \\
\hline VALLE & $\ddot{\mathrm{u}}$ & $\mathrm{X}$ & $\ddot{\mathrm{u}}$ & $\ddot{\mathrm{u}}$ \\
\hline ANTIOQUIA & $\ddot{\mathrm{u}}$ & $\mathrm{X}$ & $\ddot{\mathrm{u}}$ & $\mathrm{X}$ \\
\hline NACIONAL & $\ddot{u}$ & $\ddot{\mathrm{u}}$ & $\ddot{u}$ & $\ddot{\mathrm{u}}$ \\
\hline
\end{tabular}

Source: Authors

the expected values in three indicators were: Pedagógica, Pereira, Caldas, and Valle; Antioquia and Magdalena were efficient in two; and Atlántico only in one. 
Concerning indicators, Research Groups was attained by seven universities (Magdalena, Pedagógica, Pereira, Atlántico, Valle, Antioquia, and Nacional); Papers by six universities (Magdalena, Pereira, Caldas, Valle, Antioquia, and Nacional); Masters and Doctoral Graduates by 5 (Pedagógica, Pereira, Caldas, Valle, and Nacional); and Journals only by three universities (Pedagógica, Caldas, and Nacional). All the abovementioned universities are efficient.

For a better group perspective regarding the observed and intended values of 2012's production in terms of research, Fig. 7 illustrates the averages of the 32 universities for each indicator.

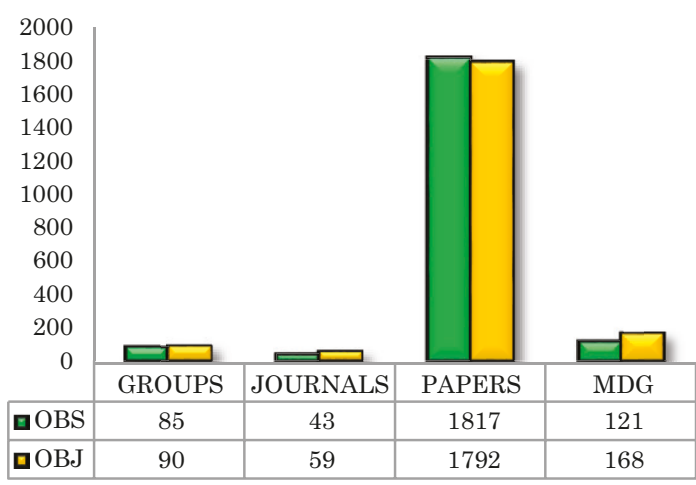

Fig. 7. Average of Observed and Intended Values for Research Indicators. Source: Authors

The intended values are above the observed values in each indicator except for the Papers indicator, demonstrating that the complete system still has to improve research performance. The good behavior in paper production is the result of the high values obtained by the Very Large universities, particularly, Universidad Nacional. In percent values, Groups, Journals, and MDG should increase in a 6,37 , and $39 \%$, respectively, in order to achieve the objectives.

\section{CONCLUSIONS}

In the analysis of the results obtained, limitations caused by the inclusion of only some research indicators (leaving aside education and extension products) must be considered. Nonetheless, this reduction in university products affects, mainly, the estimated efficiency measurement, and to a lesser extent, the comparison among units. On the other hand, the absence of the financial indicator that, as explained previously, reveals inexplicable inconsistencies, left out an input which, certainly, could help explain the efficiency achieved. To fill this void, the remaining competence indicators were studied, which, in turn, are closely linked to financial resources.
This study poses DEA's non-parametric method as a tool to measure relative efficiency of Colombian public universities. Results attained show that these institutions have an average efficiency of $75 \%$ with a high heterogeneity: universities with very high research levels, and others in an incipient (or almost inexistent) research production stage. The improvements estimated by the method are, in many occasions, of an important magnitude in the 24 universities considered as inefficient.

Although in the first years efficiency levels deficiencies were substantial, throughout the period, the distances decreased, showing that universities, with few exceptions, have started to consolidate research as a fundamental activity in education.

To sum, it can be said that the Public University System (SUE) has more research groups and publishes a suitable amount of papers, but still lacks journal creation and Masters and Doctoral graduates.

In particular, it is relevant to mention that Universidad Nacional was the only university that achieved very high values in all the indicators, surpassing intended values. For this reason, it is the best Colombian university positioned in the world university rankings.

Considering all the public universities, the indicator that has improved the most during this period is the Research Groups accredited by Colciencias, which grew from 98 points in 2003 to 2709 in 2012, almost 30 times more.

Regarding paper production, in 2003 this indicator obtained 2923 points and in 2012 it reached 58148 points, almost 20 times more. And the journal indicator passed from 191 points in 2003 to 1363 in 2012, this is, it grew a little more than 7 times in 10 years.

The only indicator that has not evidenced an improvement is the quantity of Masters and Doctoral graduates. Although the first years (2003-2006) presented a sustained increase, in the next years it showed a little growth (3\% in 2007 and $4 \%$ in 2008) until 2010, when it exhibited a decrease of $65 \%$. As a summary, in 2003, 4573 students graduated from these programs, and after 10 years, the number reduced to 3867 graduates, this represents a percent decrease of $15 \%$. The problem is that, in general, Masters and Doctoral programs in Colombian public universities are scarce; however, this tendency seems to improve due to the support programs MEN has been offering during the last years.

There are five universities without journal production, and eight universities without any MDG report during the overall period analyzed.

Despite these limitations, the results obtained are useful for the design and implementation of university policies, in particular, those related to the creation of postgraduate programs and journal production. 
It would be very interesting to carry through an analysis that includes private universities, at least the most important: those with an institutional accreditation. This research would allow identifying the best practices regarding production accomplishment and resource use to foster a better design of Colombian university policies.

\section{REFERENCES}

[1] Congreso de la Republica, Ley 30 de diciembre 28 de 1992. Colombia, 1992

[2] G. Yáñez and J. Torres, "Análisis de los Indicadores de Gestión en la Universidad Industrial de Santander en el período 2003-2008." Bucaramanga, 2010.

[3] G. Yáñez and J. Torres, "Construcción de un modelo dinámico de indicadores para el Sistema Universitario Estatal," Entornos, vol. 24, no. Especial, pp. 39-51, 2012.

[4] W. Cooper, L. Seiford, and K. Tone, Data Envelopment Analysis A Comprehensive Text with Models, Applications, References and DEA-Solver Software, 2nd ed. New York: Springer, 2006.

[5] Ministerio de Educación, "SNIES." [Online]. Available: http://www.mineducacion.gov.co/sistemasdeinformacion/1735/w3-propertyname-2672.html.

[6] C. Timothy, O. Christopher, and D. Rao, An Introduction to Efficiency and Productivity Analysis, 2nd ed. New York: Springer, 2005.

[7] R. Fuentes, "Eficiencia de la gestión de los institutos públicos de bachiller de la provincia de Alicante," $\mathrm{Ph} . \mathrm{D}$ dissertation, Dept. Econ.Cien. Univ. Alicante, 2000.

[8] M. L. Bougnol and J. H. Dulá, "Validating DEA as a ranking tool: An application of DEA to assess performance in higher education," Ann. Oper. Res., vol. 145, no. 1, pp. 339-365, Jun. 2006. DOI: 10.1007/s10479-006-0039-2.

[9] J. Johnes, "Data envelopment analysis and its application to the measurement of efficiency in higher education," Econ. Educ. Rev., vol. 25, no. 3, pp. 273-288, 2006. DOI: 10.1016/j.econedurev.2005.02.005

[10] C. T. Kuah and K. Y. Wong, "Efficiency assessment of universities through data envelopment analysis," Procedia Comput. Sci., vol. 3, pp. 499-506, 2011. DOI: 10.1016/j.procs. 2010.12.084

[11] M. Abbott and C. Doucouliagos, "The efficiency of Australian universities: a data envelopment analysis," Econ. Educ. Rev., vol. 22, no. 1, pp. 89-97, 2003. DOI: 10.1016/ S0272-7757(01)00068-1

[12] J. Johnes and L. Yu, "Measuring the research performance of Chinese higher education institutions using data envelopment analysis," China Econ. Rev., vol. 19, no. 4, pp. 679-696, 2008. DOI: 10.1016/j.chieco.2008.08.004

[13] N. K. Avkiran, "Investigating technical and scale efficiencies of Australian Universities through data envelopment analysis," Socioecon. Plann. Sci., vol. 35, no. 1, pp. 57-80, 2001. DOI: 10.1016/S0038-0121(00)00010-0

[14] A. D. Athanassopoulos and E. Shale, "Assessing the Comparative Efficiency of Higher Education Institutions in the UK by the Means of Data Envelopment Analysis," Educ. Econ., vol. 5, no. 2, pp. 117-134, 1997. DOI: $10.1080 / 09645299700000011$

[15] J. M. Gómez Sancho, "La evaluación de la eficiencia en las universidades públicas españolas," X Jornadas de la Asociación de la Economía de la Educación. Servicio de Publicaciones, pp. 411-434, 2001.
[16] M. McMillan and D. Datta, "The Relative Efficiencies of Canadian Universities: A DEA Perspective," Can. Public Policy, vol. 24, no. 4, pp. 485-511, 1998. DOI: 10.2307 / 3552021

[17] B. Taylor and G. Harris, "Relative efficiency among South African universities: A data envelopment analysis," High. Educ., vol. 47, no. 1, pp. 73-89, 2004. DOI: 10.1023/B:HIGH.0000009805.98400.4d

[18] R. Caballero, T. Galache, T. Gómez, and A. Torrico, "Análisis de la eficiencia vía DEA y multiobjetivo. Una aplicación al caso de la Universidad de Málaga." Jaen, pp. 81-96, 2000 .

[19] M. C. González Veiga, F. J. Mato Díaz, and E. Lafuente Robledo, "Estudio de la eficiencia en la Universidad de Oviedo a través del análisis envolvente de datos," VII Jornadas de la Asociación de la Economía de la Educación. Universidad de Cantabria, pp. 417-428, 1998.

[20] G. Johnes and J. Johnes, "Measuring the Research Performance of UK Economics Departments: An Application of Data Envelopment Analysis," Oxf. Econ. Pap, vol. 45, no. 2, pp. 332-47, 1993.

[21] E. Martín Villaspín, "An application of the Data Envelopment Analysis Methodology in the performance assessment of the Zaragoza University Departments." 2006.

[22] [22] Z. Sinuany-Stern, A. Mehrez, and A. Barboy, "Academic departments efficiency via DEA," Comput. Oper. Res., vol. 21, no. 5, pp. 543-556, 1994. DOI: 10.1016/0305-0548(94)90103-1

[23] C. Tomkins and R. Green, "An Experiment in the Use of Data Envelopment Analysis for Evaluating the Efficiency of UK University Departments of Accounting," Financ. Account. Manag, vol. 4, no. 2, pp. 147-164, Jun. 1988. DOI: 10.1111/j.1468-0408.1988.tb00296.x

[24] J. Johnes, "Measuring teaching efficiency in higher education: An application of data envelopment analysis to economics graduates from UK Universities 1993," Eur. J. Oper. Res., vol. 174, no. 1, pp. 443-456, 2006. DOI: 10.1016/j.ejor.2005.02.044

[25] J. E. Beasley, "Determining Teaching and Research Efficiencies," J. Oper. Res. Soc., vol. 46, no. 4, pp. 441452, 1995.DOI: 10.1057 /jors. 1995.63

[26] J. Soto Mejia, W. Arenas Valencia, and A. Trejos, "La producciòn académica como uno de los indicadores del desempeño de las universidades públicas colombianas desde la perspectiva del análisis envolvente de datos," Scientia et Technica, vol. 2, no. 28, pp. 109-114. 2005.

[27] J.-L. Pino-Mejías, F. Solís-Cabrera, M. Delgado-Fernández, and R. Barea-Barrera, "Evaluación de la eficiencia de grupos de investigación mediante análisis envolvente de datos (DEA)," El Prof. la Inf., vol. 19, no. 2, pp. 160-167, 2010. DOI: 10.3145/epi.2010.mar.06

[28] M. C. González Veiga, E. Lafuente Robledo, and F. J. Mato Díaz, "El análisis envolvente de datos y la eficiencia en la Universidad: modelos de evaluación de la docencia y la investigación." Oviedo, pp. 1-22, 1999.

[29] A. Charnes, W. W. Cooper, and E. Rhodes, "Measuring the efficiency of decision making units," Eur. J. Oper. Res., vol. 2, no. 6, pp. 429-444, 1978. DOI: 10.1016/0377-2217(78)90138-8

[30] A. Charnes, W. W. Cooper, and E. Rhodes, "Evaluating Program and Managerial Efficiency: An Application of Data Envelopment Analysis to Program Follow Through," Manage. Sci., vol. 27, no. 6, pp. 668-697, 1981. DOI: $10.1287 / \mathrm{mnsc} .27 .6 .668$ 